\title{
ANALISIS PREFERENSI VISUAL LANSKAP PESISIR DAERAH ISTIMEWA YOGYAKARTA UNTUK PENGEMBANGAN PARIWISATA PESISIR MENUJU PADA PENGELOLAAN WILAYAH PESISIR BERKELANJUTAN
}

\author{
Nurul Khakhim \\ Fakultas Geografi Universitas Gadjah Mada \\ Bulaksumur, Tlp (0274) 589595, Fax. (0274) 589595, \\ E-mail : nrl_khakim@yahoo.com

\section{Dedi Soedharma \\ Ani Mardiastuti \\ Mennofatria Boer} \\ Vincentius P. Siregar \\ Fakultas Perikanan dan Ilmu Kelautan Institut Pertanian Bogor \\ Jl. Rasamala, Kampus IPB Darmaga, Bogor 16680 \\ Telp : 0251-622907, 622911, Fax : 0251-622907 \\ E-mail: fikanipb@indo.net.id
}

\begin{abstract}
The aim of this research is to analyze of DIY coastal landscape with visual preference analysis for suistanble coastal tourism development and management. The unit of analysis that used is coastal typology. The guideline in deciding the classification of coastal typology is using the Response-Process System with relief/slope, main constructing material, genesis process and dominate process happened in the mean time such as tide, wave and river flow. This response-process system divide the coastal typology into seven classes including coastal typology of land erosion coast, sub aerial deposition coast, volcanic coast, structurally shaped coast, wave erosion coast, marine deposition coast and coast built by organism. The method of SBE (Scenic Beauty Estimation) is used for visual preference analysis, and the method used to compose the policy of costal tourism development is SWOT method. Result shows that all seven coastal typology are found in the coastal area. L and erosion coast and coast built by organism dominate in Gunungkidul coastal area and then in Bantul and Kulon Progo coastal area are dominated by marine deposition coast and sub aerial deposition coast. volcanic coast, structurally shaped coast, wave erosion coast can only be found in a small area of Gunungkidul coast. Each of this coastal typology has a special land characteristic which can be used to develop its potential. Coast built by organism is very suitable for tourism activity proved by the bigh score of SBE from the respondents. Recommendation for developing coastal area in area of interest is by developing the coastal natural resources suitable to itsphysical typology, because this will make the management of coastal area for continuous development easier. Recommendations for coastal management in Gunungkidul including mapping and classification of protected karst area and mineable karst area to secure the run of coastal area management, for coastal management in Bantul using Managed realignment which plans for retreat and adopts engineering solutions that recognise natural processes of adjustment, and identifying a new line of defence where to construct new defences and move seaword model by constructing new defenses seaward the original ones. Last, for Kulon Progo coastal area using hold the line model whereby seawalls are constructed around the coastlines.
\end{abstract}

Keyword : coastal typology, SBE (Scenic Beauty Estimation)

\section{PENDAHULUAN}

Wilayah pesisir adalah daerah pertemuan antara darat dan laut, dengan batas ke arah darat meliputi bagian daratan, baik kering maupun terendam air yang masih mendapat pengaruh sifat-sifat laut seperti angin laut, pasang surut, perembesan air laut (intrusi) yang dicirikan oleh vegetasinya yang khas, sedangkan batas 
wilayah pesisir ke arah laut mencakup bagian atau batas terluar daripada daerah paparan benua (continental shelf), dimana ciriciri perairan ini masih dipengaruhi oleh proses alami yang terjadi di darat seperti sedimentasi dan aliran air tawar, maupun proses yang disebabkan oleh kegiatan manusia di darat seperti penggundulan hutan dan pencemaran (Dahuri, 2004)

Proses fisik yang terjadi di laut dan di daratan yang terus-menerus berlangsung tentunya membentuk jenis pesisir tertentu (tipologi pesisir) tergantung pada proses genetik dan material penyusunnya, sehingga tiap tipologi pesisir tertentu akan memberikan ciri-ciri pada bentanglahan (landscape) dan berbagai macam sumberdaya yang ada di wilayah pesisir tersebut. Dengan demikian, pengelompokan (zonasi) tipologi pesisir dari aspek fisik lahan akan mempermudah dalam melakukan perencanaan dan pengelolaan pesisir secara tepat sesuai dengan kondisinya.

Pengembangan kawasan pesisir harus mengikuti pola keberlanjutan dan keterpaduan agar pemanfaatan kawasan pesisir tersebut tidak merugikan satu sama lainnya. Keberlanjutan mengandung arti integritas lingkungan, perbaikan kualitas hidup, serta keadilan antar generasi, sedangkan keterpaduan mengadung arti keterpaduan perencanaan antara nasional, provinsi, regional, dan lokal maupun keterpaduan perencanaan antar sektor pada tiap-tiap tingkat pemerintahan, seperti keterpaduan antar sektor pariwisata dan sektor perikanan di tingkat regional, dan lain-lainnya.

Dalam Agenda 21 Daerah Istimewa Yogyakarta (2004), disebutkan bahwa karakter Yogyakarta adalah pariwisata, pendidikan dan budaya, sehingga kawasan pesisir merupakan kawasan yang sangat potensial untuk dikembangkan. Kenyataan menunjukkan bahwa ada beberapa kawasan pesisir yang memang sudah dikembangkan sebagai kawasan wisata seperti di Pantai Parangtritis, Pantai Kukup, Pantai Baron, dan Pantai Glagah, namun masih sangat banyak kawasan pesisir di wilayah DIY yang sebetulnya sangat berpotensi untuk dikembangkan sebagai kawasan wisata sampai saat ini belum dikembangkan sama sekali karena memang belum ada kebijakan, penilaian dan upaya-upaya yang maksimal untuk mengembangkannya.

Adapun tujuan penelitian ini adalah:

1. Menganalisis tipologi pesisir di Provinsi Daerah Istimewa Yogyakarta

2. Menganalisis preferensi visual lanskap pesisir berdasarkan pada tipologi pesisir di wilayah pesisir Daerah Istimewa Yogyakarta

3. Mengkaji pengembangan pariwisata pesisir berkelanjutan

Menyangkut tentang klasifkasi/ tipologi pesisir, sejak tahun 1888, E.Suess (dalam Haslett 2000) mengusulkan klasifikasi berdasarkan struktur geologis (batuan) dan orientasinya dianggap sebagai kecenderungan terhadap garis pantai, sedangkan Haslett (2000) mengklasifikasikan sistem pesisir berdasarkan pada 4 sistem yaitu :

1. Sistem Morfologis : Pendekatan pada hubungan dari ekspresi morfologisnya.

2. Sistem Cascade : secara eksplisit merujuk kepada aliran energi dan zat; gerakan sedimen melalui sistem pesisir,

3. Sistem Proses-Respons: kombinasi sistem morfologi dan sistem cascade.

4. Ekosistem: interaksi antara flora dan fauna dalam lingkungan fisik pesisir. 
European Union for Coastal Conservation/EUCC (1998) menentukan tipologi pesisir (coastal typology) mendasarkan pada hubungan antara karakteristik geologi yang penting dan faktor oseanografi. Tipologi pesisir ini selanjutnya digunakan untuk menentukan sistem pesisir (coastal system) di Eropa (The Coastal System of Europe). Parameter utama dan kriteria yang digunakan untuk menentukan tipologi pesisir ini adalah :

1. Material utama di zona litoral (Predominant Substrate in the litoral zone)

- Batuan keras (hard rocks) yaitu batuan yang tahan terhadap erosi dan hampir tidak memasok material sedimen ke zona litoral, kecuali sedimen sungai.

- Batuan lunak (soft rocks) yaitu batuan yang mempunyai resistensi lebih rendah terhadap erosi.

- Sedimen terkini (recent sediment) yaitu tanah lepas terdiri dari partikel kecil dengan resistensi rendah terhadap erosi.

2. Kemiringan lereng di wilayah pesisir (slope of the coastal zone).

- Pantai terjal yaitu pantai dengan karang yang terjal dan tinggi

- Dataran pesisir, yaitu pantai dengan bentuk dataran

3. Rezim pasang surut (tidal rezim). Parameter ini memberikan pengaruh pada formasi dan evolusi dari lanskap pesisir.

- Pesisir yang didominasi oleh pengaruh pasang surut : julat pasang surut $>2 \mathrm{~m}$.

- Pesisir yang didominasi oleh gelombang: julat pasang surut $<2 \mathrm{~m}$.

- Pesisir yang didominasi oleh aliran sungai.
Pethic (1984) mengelompokkan pesisir menjadi 2 kategori, yaitu pesisir primer (primary coast) dan pesisir sekunder (secondary coast). Morfologi dalam pesisir primer lebih dikontrol oleh proses-proses darat atau terrestrial (non marine processes) seperti : erosi, deposisi, volkanik, dan diatropisme, sedangkan pesisir sekunder merupakan pesisir yang terutama dibentuk oleh aktivitas laut (marine agents) seperti gelombang, pasang surut, dan arus laut atau aktifitas organisme laut (marine organisms): seperti terumbu karang.

Pesisir primer dikelompokkan lagi menjadi 5 tipe pesisir yaitu pesisir akibat proses erosi darat (land erosion coasts), pesisir akibat proses deposisional sub arial (subaerial deposition coasts), pesisir akibat aktivitas volkanik (volcanic coasts), pesisir akibat pergerakan diastropik atau proses struktural (shaped by diastrophic movements), dan pesisir es (ice coast)_ khusus untuk pesisir es hanya terdapat di Antartika (kutub selatan); sedangkan pesisir sekunder dikelompokkan ke dalam 3 tipe pesisir, yaitu pesisir yang terbentuk oleh erosi gelombang (wave erosion coasts), pesisir yang terbentuk oleh proses pengendapan marin (marine deposition coasts), dan pesisir yang dibentuk oleh aktivitas organisme (coast built by organisms).

Kay and Alder (1999) mengemukakan pengertian lanskap (landscape) dalam 3 arti yang berbeda, yaitu lanskap dalam arti pemandangan (landscape painting), lanskap dalam arti bentanglahan dengan kenampakan bio-fisik (landscape ecology), dan lanskap dalam arti hasil interpretasi dan pengalaman lapang dari seseorang.

Keindahan suatu lanskap dapat dinikmati dengan mengamati peman- 
dangannya melalui indera penglihatan. Menurut Steinitz (1990) mengamati suatu lanskap dapat memberikan persepsi dan perasaan psikologis yang berbeda-beda serta menghadirkan nilai simbolik. Menurut Falero dan Alonzo (1995) perhatian terhadap aspek visual lanskap yang berkaitan dengan persepsi manusia merupakan salah satu pendekatan dalam perencanaan lanskap, pendekatan lainnya adalah melalui studi lingkungan dan studi lanskap secara keseluruhan. Fungsi visual dapat memberikan arti mengenai bagaimana suatu lanskap dapat memberikan reaksi bagi yang mengamatinya. Fungsi ini dipengaruhi oleh banyaknya variasi visual yang ada dalam suatu lanskap.

\section{METODE PENELITIAN}

\section{Penentuan Tipologi Pesisir}

Dasar klasifikasi tipologi pesisir adalah menurut klasifikasi yang dikemukakan oleh Haslett (2000) yaitu sistem Proses - Respon, yang merupakan kombinasi antara sistem morfologi dan sistem cascade. Sistem morfologi merujuk pada metode pengelompokan yang dilakukan oleh Pethic (1984) yang mendasarkan pada relief, material penyusun utama, proses genesis, sedangkan sistem cascade yang merujuk pada aliran energi mengacu pada penentuan tipologi pesisir yang dilakukan oleh Europen Union for Coastal Conservation/EUCC (1998) terutama pada rezim pasang surut yaitu dominasi proses yang terjadi antara pasang surut, gelombang dan sungai.

Penentuan tipologi pesisir dilakukan dengan menelusuri tiga komponen (unsur) pembentuknya yaitu materi penyusun utama, relief dan proses genesisnya (termasuk disini adalah proses yang dominan). Dalam teknik identifikasi ini, terlebih dahulu diidentifikasi reliefnya (berelief kasar atau halus), kemudian materi penyusun utamanya (material padu, material lepas/klastik, material lembek/lumpur, atau materinya organisme), setelah itu proses genesanya (struktural, vulkanik, solusional, marin, fluviomarin, aeoliomarin, biomarin). Proses marin sendiri lebih diperinci pada aktivitas gelombang atau pasang surut yang lebih dominan pengaruhnya, yaitu dengan melihat julat pasangsurutnya (apabila julat pasang-surutnya $>$ $2 \mathrm{~m}$ maka aktivitas pasang-surut yang lebih dominan, sedangkan apabila julat pasangsurutnya $<2 \mathrm{~m}$ maka aktivitas gelombang yang lebih dominan). Dengan menganalisis ketiga faktor tersebut maka dapat memudahkan dalam menentukan tipe pesisir di daerah penelitian. Sunarto (2003) memberikan cara mengidentifikasi secara geomorfologis tipe pesisir seperti tersaji dalam

\section{Gambar 1.}

\section{Analisis Preferensi Visual}

Metode analisis preferensi visual yang dapat digunakan adalah metode Scenic Beauty Estimation (SBE) yang dikemukakan oleh Daniel dan Boster (1976). Beberapa pertimbangan mengapa digunakan metode SBE ini adalah:

- Banyak penelitian visual yang menggunakan metode SBE ini dalam perhitungan nilai visualnya, hal ini disebabkan karena prosedur SBE dikenal efektif dan dapat dipercaya (Yu, 1995).

- Awal mula dikembangkannya metode SBE ini adalah untuk menilai secara visual suatu lanskap untuk pengembangan wisata kehutanan. Mendasarkan metode SBE digunakan untuk menilai secara visual lanskap, dimana wilayah pesisir juga mempunyai lanskap yang sangat potensial untuk dikembangkan dan dikelola 


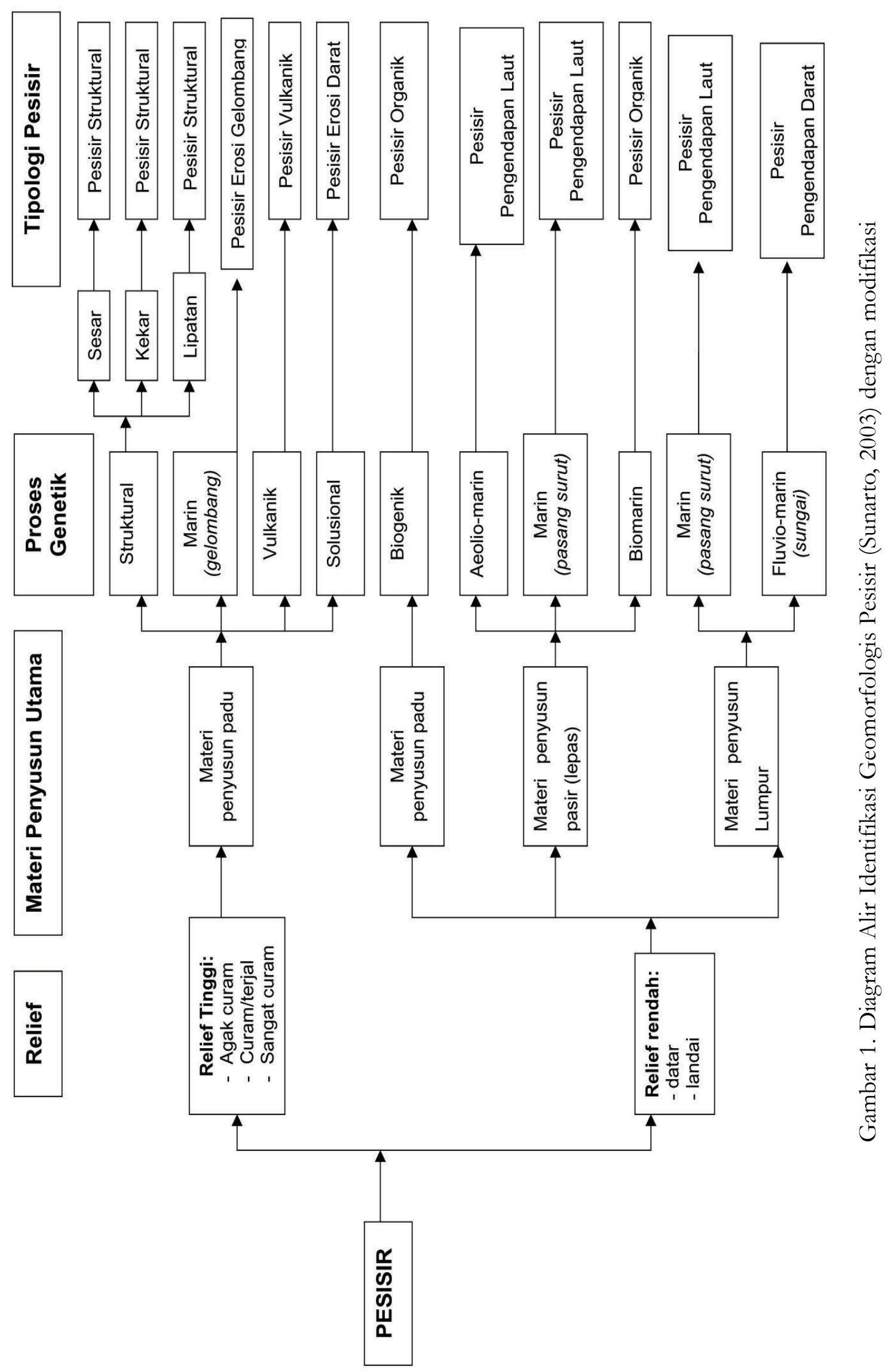


sebagai kawasan wisata pesisir (coastal tourism), maka digunakanlah metode SBE ini, dengan menyesuaikan pada kondisi dan jenis lanskap yang ada di wilayah pesisir.

- Penggunaan metode SBE untuk penilaian lanskap pesisir, sepanjang pustaka yang telah dibaca, termasuk juga pada penelusuran data melalui internet, belum pernah dilakukan, sehingga mendorong peneliti untuk menggunakan metode SBE ini dalam melakukan analisis dan pemodelan spasial sumberdaya wilayah pesisir DIY untuk pengembangan pariwisata.

Tahapan yang dilakukan dalam menentukan nilai SBE adalah :

a. Penentuan titik pengamatan dan pengambilan foto

Titik pengamatan dalam pengambilan foto ditentukan dengan memeprhatikan karakteristik lanskap wilayah pesisir pada setiap tipologi pesisir sebagai unit analisis. Titik pengamatan ini merupakan daerah terbuka/tempat yang tinggi.

b. Seleksi foto

Foto-foto yang akan dipresentasikan kepada responden merupakan hasil seleksi dari keseluruhan foto yang diambil dan ianggap paling mewakili keanekaragaman pemandangan yang dapat dilihat di sepanjang wilayah pesisir DIY

c. Penilaian oleh responden

Responden yang dipilih dalam penelitian ini adalah pengunjung wisata yang ditemui di lokasi pantai. Setiap foto ditampilkan selama 10 detik dan langsung dinilai oleh responden. Responden menilai setiap foto yang ditampilkan dengan memberikan nilai 1 sampai 10 , dimana nilai 1 menunjukkan nilai yang paling tidak disukai dan nilai 10 merupakan nilai yang paling disukai. d. Perhitungan nilai SBE

Tahapan perhitungan nilai visual dengan metode SBE diawali dengan tabulasi data, perhitungan frekuensi setiap skor (f), perhitungan frekuensi kumulatif (cf) dan cumulative probabilities (cp). Selanjutnya ditentukan nilai z untuk setiap nilai cp. Khusus untuk nilai $\mathrm{cp}=1.00$ atau $\mathrm{cp}=(\mathrm{z}= \pm ¥)$ digunakan rumus perhitungan $\mathrm{cp}=1-$ $1 /(2 \mathrm{n})$ atau $\mathrm{cp}=1 /(2 \mathrm{n})$ (Bock dan Jones, 1968 dalam Daniel dan Boster, 1976). Rata-rata nilai z yang diperoleh untuk setiap fotonya kemudian dimasukkan dalam rumus SBE:

$$
\text { SBE } x=(Z x-Z o) \times 100
$$

Dimana,

$$
\begin{aligned}
\text { SBEx }= & \text { nilai penduga nilai kein- } \\
& \text { dahan pemandangan lans- } \\
& \text { kap ke- } x \\
Z \mathrm{Zx} & \text { nilai rata-rata } \mathrm{z} \text { untuk lans- } \\
& \text { kap ke-x } \\
\mathrm{Zo}= & \text { nilai rata-rata suatu lanskap } \\
& \text { tertentu sebagai standar }
\end{aligned}
$$

\section{Analisis Pengembangan Pariwisata dan Pengelolaan Wilayah Pesisir yang Berkelanjutan}

Untuk menentukan model pengembangan ini, digunakan analisis matrik yang diilhami dari analisis SWOT. Pemilihan metode ini didasarkan kepada relevansi dari pendekatan yang dilakukan melalui metode tersebut, yang akan menghasilkan Analisis dan Pilihan Strategis (Strategic Analysis and Choices) yang merupakan asumsi-asumsi hasil analisis dan kemudian dapat digunakan untuk menentukan faktor penentu keberhasilan dan faktor ancaman kegagalan. Analisis ini didasarkan pada logika yang dapat memaksimalkan kekuatan (strengths) dan peluang (opportunities) suatu 
kegiatan, dan secara bersamaan dapat meminimalkan kelemahan (weaknesses) dan ancaman (threats).

\section{HASIL DAN PEMBAHASAN}

\section{Tipologi Pesisir}

Tipologi fisik pesisir yang terdapat di daerah penelitian ternyata bahwa di wilayah pesisir Kabupaten Gunungkidul ditemukan hampir semua tipe pesisir, dimulai dari yang paling dominan yaitu tipe pesisir erosi darat sampai pada tipe pesisir organik. Di beberapa tempat terutama di pantai yang berbentuk teluk termasuk dalam tipe pesisir pengendapan laut dan tipe pesisir organik. Kedua tipe pesisir ini dicirikan oleh relief dengan kemiringan datar sampai landai, materi penyusun utamanya berupa material lepas (pasir), dan proses genesanya marin (aktivitas laut). Perbedaan keduanya terletak pada spesifikasi materi penyusun utamanya. Tipe pesisir pengendapan laut materi utamanya adalah pasir sedimen laut, sedangkan tipe pesisir organik materi utamanya adalah pecahan karang (organisme laut). Tipe pesisir volkanik, struktural, dan erosi gelombang dijumpai di beberapa tempat yang spesifik, ditandai dengan ditemukannya kenampakan yang menonjol dari proses genesis tersebut di lapangan. Tipe pesisir volkanik terdapat di sebelah timur Pantai Siung sampai Pantai Wediombo. Diantara ke dua pantai tersebut, terdapat Gunung Batur yang merupakan bagian dari satuan panggung masif berbatuan sedimen volkanik klastik berumur tersier. Kenampakan yang cukup menonjol adalah terlihatnya batuan sedimen volkan di Pantai Wediombo. Tipe pesisir struktural dijumpai di Pantai Ngobaran dengan kenampakan struktural berupa patahan yang terjal, se- dangkan tipe pesisir erosi gelombang terdapat di Pantai Ngungap, yang juga ditandai dengan kenampakan yang khas berupa proses erosi gelombang.

Tipologi pesisir yang terdapat di wilayah Kabupaten Bantul dan Kulon Progo yang dominan adalah tipe pesisir pengendapan laut dan beberapa tempat seperti di kanan kiri sungai merupakan tipe pesisir pengendapan darat. Tipe pesisir pengendapan laut bercirikan relief yang dataran hingga berombak, mempunyai materi pasir, dan prosesnya terdiri dari proses marin (gelombang) untuk wilayah yang dekat dengan laut dan proses aeolian (angin) pada daerah yang lebih ke arah darat. Kenampakan yang mudah untuk dikenali di lapangan adalah kenampakan gisik pantai (untuk proses marin) dan gumuk pasir (untuk proses aeolian). Tipe pesisir pengendapan darat dicirikan oleh relief dataran hingga berombak, dengan materi berupa lumpur (lembek), dan proses genesisnya berupa proses fluvial (aliran sungai). Sebaran tipologi pesisir yang ada di daerah penelitian disajikan dalam Tabel 1 dan Pada Peta Tipologi Pesisir DIY.

\section{Preferensi Visual Lanskap Wilayah Pesisir}

Hasil dari penilaian kualitas visual oleh responden merupakan skor untuk masing-masing foto. Rata-rata nilai yang diperoleh dari hasil penilaian responden kemudian dimasukkan dalam rumus SBE (Tabel 2). Skor tertinggi (nilai SBE tinggi) menunjukkan bahwa lanskap tersebut paling banyak dipilih sebagai lanskap yang indah, sedangkan skor rendah (nilai SBE rendah) menggambarkan lanskap yang jelek (tidak disukai). 
Tabel 2. Perhitungan Nilai SBE

\begin{tabular}{|c|c|c|c|c|c|c|c|c|c|c|c|c|c|c|}
\hline \multicolumn{5}{|c|}{ Lanskap/Foto 49} & \multicolumn{5}{|c|}{ Lanskap/Foto 3} & \multicolumn{5}{|c|}{ Lanskap/foto 69} \\
\hline Skor & $\mathrm{f}$ & cf & $\mathrm{cp}$ & $\mathbf{Z}$ & Skor & $f$ & cf & $\mathrm{cp}$ & $z$ & Skor & $f$ & cf & $\mathrm{Cp}$ & $\mathbf{z}$ \\
\hline 1 & 13 & 50 & 1 & - & 1 & 0 & 50 & 1 & - & 1 & 0 & 50 & 1 & - \\
\hline 2 & 3 & 37 & 0,74 & 0,65 & 2 & 0 & 50 & 1 & 2,33 & 2 & 0 & 50 & 1 & 2,33 \\
\hline 3 & 6 & 34 & 0,68 & 0,47 & 3 & 0 & 50 & 1 & 2,33 & 3 & 0 & 50 & 1 & 2,33 \\
\hline 4 & 7 & 28 & 0,56 & 0,16 & 4 & 7 & 50 & 1 & 2,33 & 4 & 1 & 50 & 1 & 2,33 \\
\hline 5 & 6 & 21 & 0,42 & $-0,20$ & 5 & 6 & 43 & 0,86 & 1,09 & 5 & 0 & 49 & 0,98 & 2,06 \\
\hline 6 & 7 & 15 & 0,3 & $-0,52$ & 6 & 20 & 37 & 0,74 & 0,65 & 6 & 0 & 49 & 0,98 & 2,06 \\
\hline 7 & 5 & 8 & 0,16 & $-0,99$ & 7 & 8 & 17 & 0,34 & $-0,41$ & 7 & 2 & 49 & 0,98 & 2,06 \\
\hline 8 & 2 & 3 & 0,06 & $-1,55$ & 8 & 5 & 9 & 0,18 & $-0,91$ & 8 & 13 & 47 & 0,94 & 1,56 \\
\hline 9 & 1 & 1 & 0,02 & $-2,05$ & 9 & 4 & 4 & 0,08 & $-1,39$ & 9 & 12 & 34 & 0,68 & 0,47 \\
\hline 10 & 0 & 0 & 0 & $-2,33$ & 10 & 0 & 0 & 0 & $-2,33$ & 10 & 22 & 22 & 0,44 & $-\overline{15}$ \\
\hline \multicolumn{5}{|c|}{$\sum Z=-6,36$} & \multicolumn{5}{|c|}{$\sum \mathrm{Z}=5,2$} & \multicolumn{5}{|c|}{$\sum \mathrm{Z}=15,05$} \\
\hline \multicolumn{5}{|c|}{$Z=-0,71$} & \multicolumn{5}{|c|}{$\mathrm{Z}=0,58$} & \multicolumn{5}{|c|}{$Z=1,67$} \\
\hline \multicolumn{5}{|c|}{$\begin{array}{l}\text { SBE }=(-0,71-(-0,71)) \times 100 \\
=0,00\end{array}$} & \multicolumn{5}{|c|}{$\begin{array}{l}\mathrm{SBE}=(0,58-(-0,71)) \times 100 \\
=129\end{array}$} & \multicolumn{5}{|c|}{$\begin{array}{l}\text { SBE }=(1,67-(-0,71)) \times 100 \\
=238,22\end{array}$} \\
\hline
\end{tabular}

Perhitungan nilai SBE untuk foto lanskap menunjukkan bahwa nilai tertinggi SBE yang diperoleh adalah 238,22 dan nilai terendah adalah 0,00 . Dari sebaran nilai SBE untuk semua foto yang dinilai, apabila

\begin{tabular}{|c|c|c|}
\hline Nilai SBE dibuat kl & asifikasi menjadi & yaitu nila \\
\hline 0,00 - 79, gutnakan & jenjangendakerhan & - (simplified \\
\hline 79,42 - 158,8Bgan $r$ & umusSedang & \\
\hline $158,84-238,22$ & Tinggi & tend \\
\hline
\end{tabular}

Sehingga kelas interval untuk foto yang diambil dari darat adalah

$$
I=\frac{238,22-0,00}{3}=79,41
$$

Dari hasil pengklasifikasian menggunakan jenjang sederhana tersebut, maka masing-masing foto lanskap dengan nilai SBE-nya yang menunjukkan tipologi fisik pesisir dan lokasinya dapat dibuat tabel seperti yang tersaji pada Tabel 3. Jika dibuat grafik (Gambar 4) yang menunjukkan hubungan antara nilai SBE dengan tipologi fisik pesisirnya, ternyata bahwa tipologi fisik pesisir organik mempunyai nilai SBE rata-rata lebih tinggi jika tinggi dibandingkan dengan tipologi fisik pesisir yang lain. Aspek yang menonjol dari tipologi fisik pesisir organik yang menjadikan nilai SBE-nya tinggi adalah pada kenampakan visual pasir putih yang sangat sesuai untuk kegiatan wisata. Dilihat dari penyebaran lokasi foto lanskap, ternyata bahwa lanskap pesisir organik di wilayah pesisir Kab. Gunungkidul sangat mendominasi nilai SBE yang tinggi dibandingkan dengan Kab. Bantul dan Kulon Progo. 


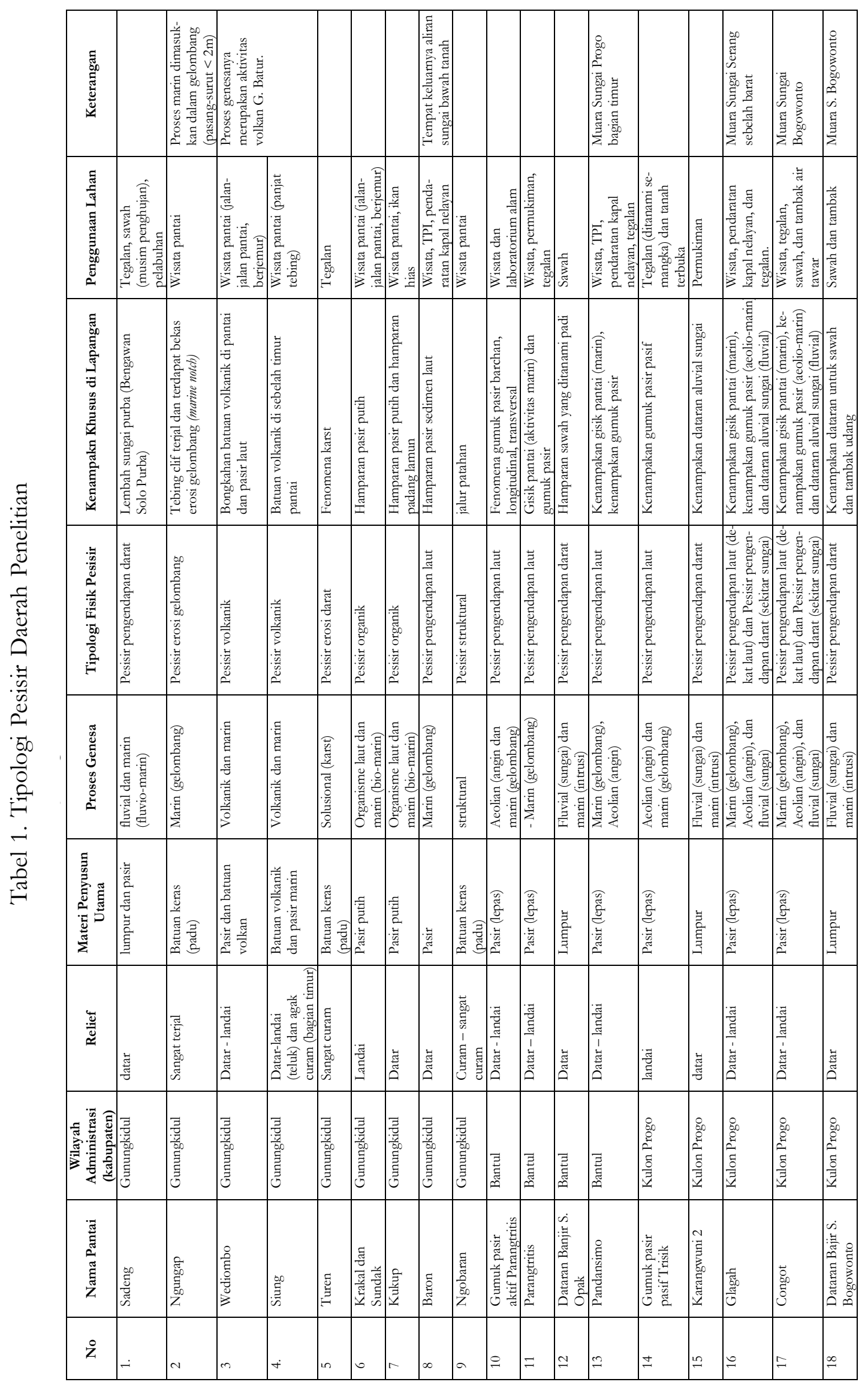


Gambar 4. Grafik Hubungan antara Tipologi Pesisir dengan Nilai SBE

\section{Pengembangan Pariwisata dan Penge- lolaan Wilayah Pesisir}

Dalam melakukan analisis rekomendasi ini, metode yang digunakan adalah

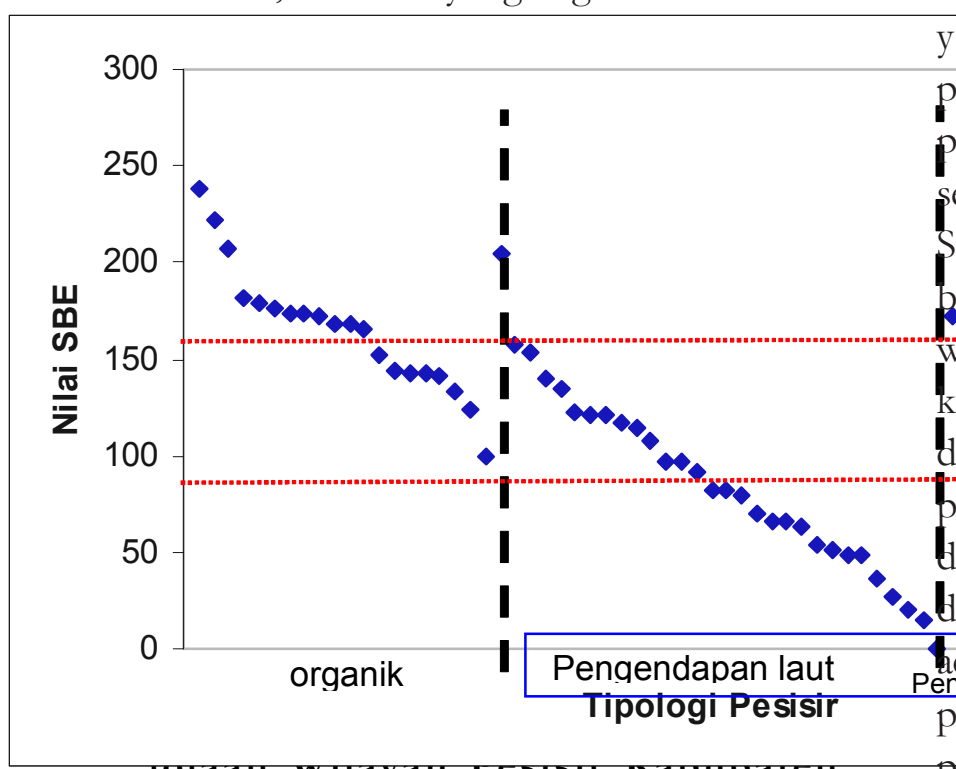

\section{Gunungkidul}

Mendasarkan analisis SWOT pada Tabel 4, rekomendasi pengembangan wilayah pesisir Kabupaten Gunungkidul adalah untuk kegiatan pariwisata pada semua tipologi pesisir dengan memanfaatan keindahan pan- orama yang khas di wilayah pesisir. Dari hasil penilaian menggunakan metode SBE, ternyata bahwa tipologi pesisir organic di Kabupaten Gunungkidul mempunyai nilai yang tinggi, sehingga pengembangan pariwisata lebih ditekankan pada wilayah pesisir yang mempunyai tipologi organic seperti di Pantai Krakal, Kukup, Sundak, dan sepanjary Langkah-langkah untuk mengemzangkan tersebut actakakgemelalui promosi

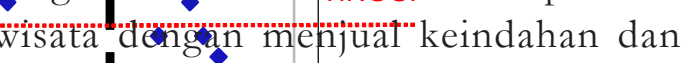

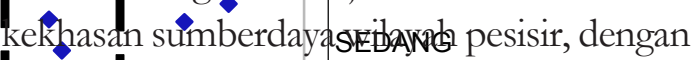
diaw i penyusunan basis data (database) potensisumberdaya pesisir untuk kemudian li uploal ke internet, \$EENHEAtd promosi dapat dilakukin secara internasional. Selanjutnya

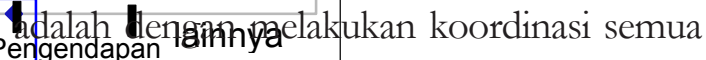
pidiarlatuntuk bersama-sama memajukan sektor pariwisata di wilayah pesisir Kabupaten Gunungkidul. Pemerintah daerah berperan dalam mengoptimalkan kegiatan promosi wisata, pembangunan sarana prasarana penunjang pariwisata, sedangkan masyarakat dan swasta berperan dalam menambah nilai kualitas kunjungan wisata . 
Tabel 3. Nilai SBE pada setiap Tipologi Fisik Pesisir

\begin{tabular}{|c|c|c|c|}
\hline $\begin{array}{l}\text { KELAS } \\
\text { SBE }\end{array}$ & NILAI SBE & $\begin{array}{c}\text { TIPOLOGI PESISIR } \\
\text { (nama pantai) }\end{array}$ & WILAYAH ADMINISTRASI \\
\hline \multirow{19}{*}{ TINGGI } & 238,22 & Organik (Sepanjang) & Kabupaten Gunungkidul \\
\hline & 221,78 & Organik (Krakal) & Kabupaten Gunungkidul \\
\hline & 207,9 & Erosi gelombang (Ngungap) & Kabupaten Gunungkidul \\
\hline & 207,11 & Organik (Kukup) & Kabupaten Gunungkidul \\
\hline & 206.78 & Pengendapan darat (Glagab) & Kabupaten Kulon Progo \\
\hline & 204.3 & Pengendapan darat (Glagah) & Kabupaten Kulon Progo \\
\hline & 202.67 & Erosi darat (Ngobaran) & Kabupaten Gunungkidul \\
\hline & 181.4 & Organik (Ngrenehan) & Kabupaten Gunungkidul \\
\hline & 180.4 & Erosi gelombang (Ngungap) & Kabupaten Gunungkidul \\
\hline & 179.33 & Organik (Sadranan) & Kabupaten Gunungkidul \\
\hline & 176 & Organik (Krakal) & Kabupaten Gunungkidul \\
\hline & 173.6 & Organik (Nguyahan) & Kabupaten Gunungkidul \\
\hline & 172.89 & Organik (Ngrenehan) & Kabupaten Gunungkidul \\
\hline & 172.7 & Volkanik (Wediombo) & Kabupaten Gunungkidul \\
\hline & 172.4 & Pengendapan laut (Parangtritis) & Kabupaten Bantul \\
\hline & 171.67 & Organik (Krakal) & Kabupaten Gunungkidul \\
\hline & 168.8 & Organik (Kukup) & Kabupaten Gunungkidul \\
\hline & 168.56 & Organik (Krakal) & Kabupaten Gunungkidul \\
\hline & 165.2 & Organik (Siung) & Kabupaten Gunungkidul \\
\hline \multirow{29}{*}{ SEDANG } & 157.1 & Pengendapan laut (Baron) & Kabupaten Gunungkidul \\
\hline & 155 & Erosi darat (Slili) & Kabupaten Gunungkidul \\
\hline & 154.1 & Volkanik (Wediombo) & Kabupaten Gunungkidul \\
\hline & 154 & Pengendapan laut (Parangtritis) & Kabupaten Bantul \\
\hline & 152.6 & Erosi darat (Slili) & Kabupaten Gunungkidul \\
\hline & 152.44 & Organik (Kukup) & Kabupaten Gunungkidul \\
\hline & 144.33 & Volkanik (Wediombo) & Kabupaten Gunungkidul \\
\hline & 144.2 & Organik (Krakal) & Kabupaten Gunungkidul \\
\hline & 143.11 & Organik (Kukup) & Kabupaten Gunungkidul \\
\hline & 143.1 & Organik (Kukup) & Kabupaten Gunungkidul \\
\hline & 142.7 & Pengendapan darat (Sadeng) & Kabupaten Gunungkidul \\
\hline & 140.67 & Organik (Kukup) & Kabupaten Gunungkidul \\
\hline & 139.9 & Pengendapan laut (Parangtritis) & Kabupaten Bantul \\
\hline & 136.2 & Pengendapan darat (Trisik) & Kabupaten Kulon Progo \\
\hline & 134.7 & Erosi darat (Ngobaran) & Kabupaten Gunungkidul \\
\hline & 134 & Pengendapan laut (Glagah) & Kabupaten Kulon Progo \\
\hline & 133.6 & Organik (Kukup) & Kabupaten Gunungkidul \\
\hline & 129 & Pengendapan darat (Congot) & Kabupaten Kulon Progo \\
\hline & 124.3 & Organik (Kukup) & Kabupaten Gunungkidul \\
\hline & 123 & Pengendapan laut (Depok) & Kabupaten Bantul \\
\hline & 123 & Pengendapan laut (Baron) & Kabupaten Gunungkidul \\
\hline & 121.22 & Pengendapan laut (Glagah) & Kabupaten Kulon Progo \\
\hline & 121.22 & Pengendapan laut (Sadeng) & Kabupaten Gunungkidul \\
\hline & 120.11 & Pengendapan darat (Congot) & Kabupaten Kulon Progo \\
\hline & 117 & Pengendapan laut (Congot) & Kabupaten Kulon Progo \\
\hline & 116.6 & Pengendapan darat (Karangwuni) & Kabupaten Kulon Progo \\
\hline & 113.9 & Pengendapan laut (Depoke) & Kabupaten Bantul \\
\hline & 107.1 & Pengendapan laut (Karangwuni) & Kabupaten Kulon Progo \\
\hline & 99.11 & Organik (Krakal) & Kabupaten Gunungkidul \\
\hline \multirow{16}{*}{ RENDAH } & 80 & Pengendapan laut (Parangtritis) & Kabupaten Bantul \\
\hline & 69.33 & Pengendapan laut (Parangtritis) & Kabupaten Bantul \\
\hline & 66.78 & Pengendapan darat (Depok) & Kabupaten Bantul \\
\hline & 66.22 & Pengendapan laut (Depok) & Kabupaten Bantul \\
\hline & 66.11 & Pengendapan laut (Depok) & Kabupaten Bantul \\
\hline & 63.89 & Pengendapan laut (Parangtritis) & Kabupaten Bantul \\
\hline & 53.22 & Pengendapan laut (Trisik) & Kabupaten Kulon Progo \\
\hline & 51 & Pengendapan laut (Trisik) & Kabupaten Kulon Progo \\
\hline & 48.11 & Pengendapan laut (Parangtritis) & Kabupaten Bantul \\
\hline & 47.89 & Pengendapan laut (Congot) & Kabupaten Kulon Progo \\
\hline & 35.78 & Pengendapan laut (Parangtritis) & Kabupaten Bantul \\
\hline & 26.33 & Pengendapan laut (Bugel) & Kabupaten Kulon Progo \\
\hline & 24.33 & Volkanik (Parangwedang) & Kabupaten Bantul \\
\hline & 20.33 & Pengendapan laut (Parangtritis) & Kabupaten Bantul \\
\hline & 14.22 & Pengendapan laut (Parangtritis) & Kabupaten Bantul \\
\hline & 0.00 & Pengendapan laut (Parangtritis) & Kabupaten Bantul \\
\hline
\end{tabular}

Sumber: Hasil Analisis Data Lapangan, 2008 
Tabel 4. Matriks SWOT Analisis Rekomendasi Pengembangan dan Pengelolaan Wilayah Pesisir Kabupaten Gunungkidul




wilayah pesisir Kabupaten Bantul dan Kabupaten Kulon Progo adalah menyesuaikan pada tipologi pesisirnya. Kegiatan pariwisata dapat dikembangkan pada semua tipologi pesisir yang ada, terutama pada tipologi pesisir pengendapan laut termasuk bentulahan gumuk pasir yang dibentuk oleh proses angin. Kegiatan perikanan model biocrete dan pertanian lahan pasir dapat dikembangkan pada tipologi pesisir pengendapan laut. Pembangunan pelabuhan dapat dikembangkan pada tipologi pesisir pengendapan laut dan tipologi pesisir pengendapan darat dengan memanfaatkan aliran sungai untuk menunjang kegiatan pelabuhan. Desain pembangunan pelabuhan dibuat dengan memperhatikan laju sedimentasi dari darat, perilaku arus dan gelombang.

Tabel 5. Matriks SWOT Analisis Kebijakan Pengembangan dan Pengelolaan Wilayah Pesisir Kabupaten Bantul dan Kulon Progo 
Pengelolaan wilayah pesisir di Kabupaten Bantul mengikuti pada strategi pengelolaan Managed realignment dan move seaword. Strategi Managed realignment terutama diterapkan di pantai Parangtritis dan sekitarnya dimana ditemukan bangunan-bangunan permukiman penduduk yang dekat dengan laut dan sering terkena gelombang pasang. Cara ini sudah mulai dilakukan oleh Pemerintah Daerah Kabupaten Bantul yang melakukan relokasi permukiman penduduk yang letaknya $<150 \mathrm{~m}$ dari garis pantai, dan pemerintah daerah Kabupaten Bantul sudah membuat aturan yang melarang pendirian bangunan permukiman pada jarak $<200 \mathrm{~m}$ dari garis pantai.

Strategi pengelolaan move seaword dipilih terutama berkaitan dengan keberadaan dan kelangsungan proses pembentukan gumuk pasir (sand dunes) aktif di Pantai Parangtritis. Fungsi gumuk pasir disamping bentuk panoramanya yang khas sehingga sangat cocok untuk pariwisata, juga mampu untuk meredam energi gelombang yang sampai ke arah darat. Ini artinya bahwa dengan membiarkan dan membebaskan gumuk pasir terbentuk secara alami maka akan mampu untuk melindungi wilayah pesisir secara keseluruhan beserta dengan sumberdaya yang ada di atasnya.

Strategi pengelolaan wilayah pesisir Kabupaten Kulon Progo adalah strategi pengelolaan hold the line pada tipologi pesisir pengendapan laut yaitu upaya pengelolaan wilayah pesisir dengan cara membuat bangunan (talut) sepanjang garis pantai untuk menahan gelombang laut. Talut ini dapat dalam bentuk bangunan fisik ataupun dalam bentuk penanaman vegetasi yang mampu menahan gelombang laut dan cocok untuk ditanam pada substrat pasir seperti cemara udang.

\section{KESIMPULAN}

Berdasarkan hasil penelitian yang telah dilakukan, dapat ditarik kesimpulan :

1. Tipologi pesisir di Provinsi Daerah Istimewa Yogyakarta dikelompokkan menjadi tujuh yaitu tipologi pesisir erosi darat (mendominasi dan hanya terdapat di wilayah pesisir Kabupaten Gunungkidul), pesisir pengendapan darat (hanya terdapat di wilayah pesisir Kabupaten Bantul dan Kulon Progo), pesisir volkanik, pesisir struktural, dan pesisir erosi gelombang (hanya terdapat di sebagian kecil wilayah pesisir Kabupaten Gunungkidul), pesisir pengendapan laut, dan pesisir organik.

2. Hasil analisis preferensi visual menunjukkan bahwa pesisir organik sangat sesuai untuk pariwisata dibuktikan dengan nilai SBE (Scenic Beauty Estimation) yang relatif tinggi untuk semua foto lanskap yang dinilai oleh responden pengunjung wisata pantai.

3. Pengembangan pariwisata lebih ditekankan pada tipologi pesisir organik dan tipologi pengendapan laut, sedangkan pada tipologi pesisir erosi gelombang, volkanik dan struktural lebih ditekankan pada pengembangan pariwisata minat khusus seperti panjat tebing sesuai dengan karakteristik lahannya berupa tebing yang sangat curam dan berbatuan keras. 


\section{DAFTAR PUSTAKA}

Dahuri, R, Jacub Rais, Sapta P.G., dan Sitepu. 2004. Pengelolaan Sumberdaya Wilayah Pesisir dan Lautan Secara Terpadu. Edisi Revisi.PT. Pradnya Paramita. Jakarta.

Daniel, T.C., and R.S. Boster., 1976. Measuring Landscape Aesthetics : The Scenic Beauty Estimation Method. USDA Forest Service Research Paper RM-167.66p.

Eitner, M.J., and T.C. Daniel. 1997. Vista Scenic Beauty Estimation Modelling : AGIS Approach. http://gis.esri.com/library/userconf/proc97/proc97/to250/pap202/p202.htm

European Union for Coastal Conservation/EUCC. 1998. Coastal Typology. http:// www.coastalguide.org/typology/

Falero, E.M., and S.G. Alonzo. 1995. Quantitative Techniques in Landscape Planning. CRC Press Inc. USA. 273 p.

Haslett, S.K. 2000. Coastal System. Routledge, New York

Higuchi, T. 1989. The Visual and Spatial Structure of Landscapes. Gibodo Publishing Co.Ltd., Tokyo. 2-5 p.

Jumadi dan Kuswaji Dwi Priyono. 2005. Analisis Kerentanan Kerusakan Terumbu Karang di Perairan Kepulauan Karimunjawa dengan Bantuan Sistem Informasi Geografis (SIG). Forum Geografi. Vol. 19 No.1 Juli 2005. Hlm 67-80.

Kay, R., and J. Alder, 1999. Coastal Planning and Management. An Imprint of Routledge. London and New York.

Nurul Khakhim, Dulbahri, Valentina Arminah, dan Andri Kurniawan. 2005. Pendekatan Sel Sedimen menggunakan Citra Penginderaan Jauh sebagai Dasar Penataan Ruang Wilayah Pesisir (Studi Kasus di wilayah Pesisir Utara Propinsi Jawa Tengah). Geografi Indonesia. ISSN 0852-2682. September 2005

Santoso, Langgeng Wahyu. 2005. Identifikasi Kerusakan Lahan dan Cara Penanganannya di Zona Perbukitan Baturagung Kabupaten Gunungkidul. Forum Geografi. Vol. 19 No.1 Juli 2005. Hlm 30-54.

Steinitz, C. 1990. Toward a Sustainable Landscape With High Visual Preference and High Ecological Integrity. Landscape Urban Planning. 19:213-250 p.

Sunarto, 1999. Sumberdaya Lanskap dalam Pengembangan Kepariwisataan di Indonesia. Fakultas Geografi UGM. Yogyakarta

Yu, 1994.Cultural Variation in Landscape Preference : Comparisons Among Chinese SubGroup and Western Design Expert. Landscape n Urban Planning 32. 107 - 126 p. 


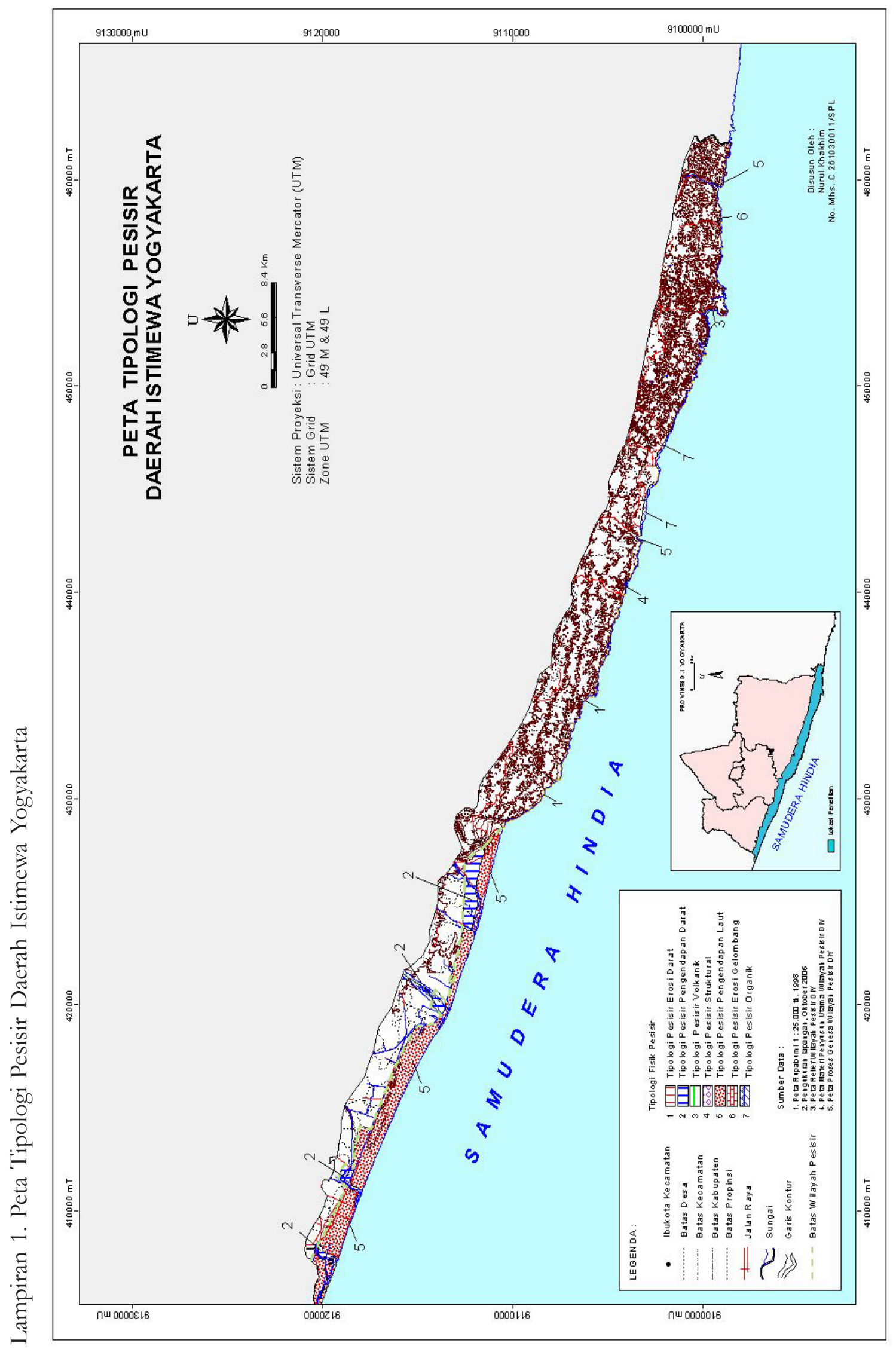

Analisis Preferensi Visual Lanskap Pesisir Daerah ... (Nurul Khakim, dkk.) 